\title{
Aggressive universal calcinosis complicating dermatomyositis
}

\section{Siham Belmourida, Hind Palamino, Mariame Meziane, Nadia Ismaili, Laila Benzekri, Badredine Hassam, Karima Senouci}

Department of Dermatology-Venerology, Mohammed V Universiy, Ibn Sina Hospital, Rabat, Morroco

Corresponding author: Dr. Siham Belmourida, E-mail: belmouridasiham2017@gmail.com

Sir,

Cutaneous calcinosis rarely complicates adult's dermatomyositis and raises the problem of medical management. Complication that can be very disabling. Its appearance is most often late, its physiopathology still little known and its treatment remains difficult $[1,2]$.

We report the case of a woman with a (DM) complicated by calcinosis remarkable for its early onset and its universal extension.

56-year-old female patient, without ATCD, followed since 2010 for (DM) treated with corticosteroids, methotrexate, endoxan and immunoglobulins with good evolution. A year later, when the clinical and biological muscular syndrome had regressed, appeared subcutaneous nodules of 1 to $3 \mathrm{~cm}$ in diameter on the trunk, back, armpits and the root of the thighs, these nodules complicated after by fistulization and ulceration (Figs. la and lb). The soft tissue radiograph and the biopsy confirmed the diagnosis of calcinosis. After 5 years of evolution, the calcinosis became universal and the treatment of the latter was disappointing, despite the prolonged intake of calcium channel blockers and colchicine. Faced with the scalability of calcinosis that stiffened all these members with the installation of amyotrophy especially in the thighs, a surgical cure was made with good evolution. This treatment resulted in a partial improvement. Currently, the patient is stabilized concerning her dermatomyositis but she has major disabling sequelae with a new thrust of universal calcinosis.

Adult's dermatomyositis rarely associates with subcutaneous calcinosis, as opposed to the juvenile

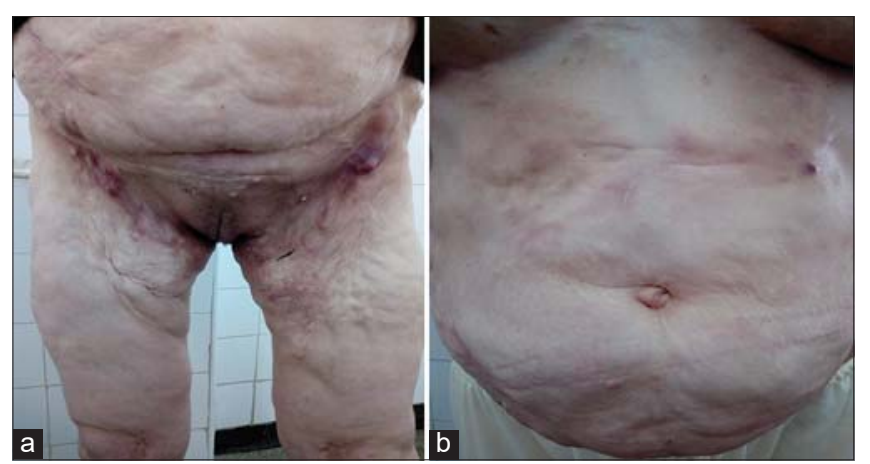

Figure 1: $(a$ and $b)$ Clinical images showing profuse skin calcifications all over the body causing a major psychomotor disability.

form. Its pathophysiology is not identified [1-3]. Calcinosis in adults is extensive, sometimes disabling. Despite remission of myositis as in our patient. Different drugs have been used for the treatment of calcinosis: colchicine, probenecid, aluminium hydroxide, dialtiazem, intraveinenous immunoglobulin, bisphosphonates and anti TNF alpha, with variable results [1-4], but no conclusion has been made because of the small number of patients and the unpredictable natural history of calcinos with possible spontaneous emittances [3].

The prognosis of subcutaneous calcinosis in adults is reserved in relation to the juvenile form [2]. Our observation is special because it presented two exceptional clinical facts during adult dermatomyositis: cutaneous calcinosis and cutaneous ulcers. Cutaneous ulcerations were mostly reported during the child's dermatomyositis. They are most often associated with calcinosis. They would be due to vasculitis.

\footnotetext{
How to cite this article: Belmourida S, Palamino H, Meziane M, Ismaili N, Benzekri L, Hassam B, Senouci K. Aggressive universal calcinosis complicating dermatomyositis. Our Dermatol Online. 2020;11(e):e140.1-e140.2.

Submission: 17.06.2020; Acceptance: 05.09.2020

DOI: 10.7241 /ourd.2020e.140
} 
In adult, dermatomyositis can exceptionally be complicated by universal calcinosis. The latter is a disabling condition whose treatment remains disappointing but a rituximab-type biotherapy could in some studies be effective.

\section{Consent}

The examination of the patient was conducted according to the principles of the Declaration of Helsinki.

The authors certify that they have obtained all appropriate patient consent forms, in which the patients have given consent for images and other clinical information to be included in the journal. The patients understand that their names and initials will not be published and due effort will be made to conceal their identity, but that anonymity cannot be guaranteed.

\section{REFERENCES}

1. Daada S, Aounallah A, Mzabi A, Ghariani N, Saidi W, Boussofara L, et al. La calcinose universelle, une complication rare et invalidante de la dermatomyosite de l'adulte. Rev Méd Int. 2015;03:65.

2. Katsuyuki Shinjo S, de Souza FHC. Update on the treatment of calcinosis in dermatomyositis. Rev Bras Reumatol. 2013;53:211-4.

3. Ambler GR, Chaitow J, Rogers M, Mcdonald DW, Ouvrier RA. Rapid improvement of calcinosis in juvenile dermatomyotisis with alendronate therapy. J Rheumatol. 2005;32:1837-9.

4. Hideki N, Kawakami A, Ida H, Ejima E, Origuchi T, Eguchi K. Efficacy of probenecid for a patient with juvenile dermatomyotisis complicated with calcinosis. J Rheumatol. 2006;33:1691-3.

Copyright by Siham Belmourida, et al. This is an open-access article distributed under the terms of the Creative Commons Attribution License, which permits unrestricted use, distribution, and reproduction in any medium, provided the original author and source are credited. Source of Support: Nil, Conflict of Interest: None declared. 